\title{
A CROSS-SECTIONAL STUDY ANALYSING THE LEVEL OF DEPRESSION AND ITS CAUSATIVE FACTORS AMONG PATIENTS VISITING A MULTISPECIALTY HOSPITAL
}

\author{
A K Prashanth, M Perathu Kannu Rakesh, V Praveena, A Preethi, S Prithvi, R \\ Priyadharshini, K Suvetha
}

Department of Community Medicine, PSG Institute of Medical Sciences and Research, Coimbatore, India

\begin{abstract}
Depression is a pathological state of the mind characterised lack of self-confidence and self-esteem. The cause of depression is multifactorial and various physical, psychological, environmental and genetic factors have been implicated in the causation of depression. Despite being a serious condition in all age groups, depression is more common and significant in the geriatric population as it is associated with significant morbidity and mortality. Various scales have been developed to assess depression of which the Geriatric Depression Scale is most suited for elderly population. It has a long form and short form, the latter being more appropriate for elderly patients with dementia. In our study, we aim to analyse the prevalence of depression among elderly patients visiting the outpatient departments of a tertiary care hospital and determine the factors influencing depression in them. The study was an Observational crosssectional study carried out on 51 elderly patients over the age of 60 years attending the various outpatient departments of PSG Hospital. The Geriatric Depression Scale Short form was used to determine the prevalence of depression. A self-designed questionnaire considering various factors causing depression was administered to determine the factors influencing depression. It was found that among 51 elders in the age group of 60 to 80 years, 58.8\% were depressed of which 54\% were males and $68 \%$ were females. Financial fears regarding future and income insufficiency were the most important factors contributing to depression. This shows that monetary fear is a major factor resulting in depression. The most effective strategy to combat depression is to ensure appropriate self-report. The government and other organizations must ensure that better support, both financial and other services like healthcare are provided to the elderly in order to prevent depressive illnesses.
\end{abstract}

\section{KEYWORDS}

Depression, Elderly, Geriatric population, The Geriatric Depression Scale.

\section{INTRODUCTION}

Depression is a condition characterised by feeling sad, miserable and down in the dumps. It is state of amotivation and loss of interest in self and the surroundings. People who are depressed have no self-confidence or self-esteem [1]. Studies have shown that depression is very prevalent among the geriatric age group and is a common cause of disability in them. In elderly persons, depression as a disease state is grossly underdiagnosed and untreated. Its presentation, manifestations and management in the geriatric age group is different from that for normal individuals [2]. Among its consequences are reduced life satisfaction and quality, social deprivation, loneliness, cognitive decline, impairments in activities of daily living, suicide and increased mortality [3]. 
Advanced Medical Sciences: An International Journal (AMS), Vol 2, No.4, November 2015

Some of the known social factors of depression include chronic illnesses, disability, prolonged drug therapy and loneliness [R]. Most likely, depression is caused by a combination of genetic, biological, environmental and psychological factors. Depressive illnesses are disorders of the brain and longstanding theories about depression suggest that important neurotransmitter chemicals that the brain cells use to communicate are out of balance in depression [4]

Several scales are used to assess depression. They include Hamilton Depression Rating Scale, Beck Depression Inventory, The Geriatric Depression Scale (GDS) and Montgomery-Asberg Depression Rating Scale [5] [6] [7] [8]. The GDS is a self-administered scale that has been extensively tested and used in elderly patients and for patients with mild to moderate dementia. The GDS Long form is a 30 point questionnaire in which the patients are asked to give a yes or no answer in reference to how they felt over the past week. A score of 0-9 was considered normal. 10-19 was considered mild depression and 20-30 as severe depression [9]. A short form of GDS consisting of 15 questions (GDS-15) was also developed which was more suited for patients with dementia because of their relatively short memory and attention span. A score of 5-8 suggests mild depression, 9-11 denotes moderate depression and 12-15 means the patient suffers from severe depression [10].

In our study, we aim to determine the prevalence of depression among elderly patients visiting the outpatient departments of PSG Hospital, which a tertiary care multispecialty hospital. The possible factors responsible for depression among geriatric patients were also analysed.

Patient's Name: Date:

Instructions: Choose the best answer for how you felt over the past week.

\begin{tabular}{|c|l|l|l|}
\hline No. & Question & Answer & Score \\
\hline \hline 1. & Are you basically satisfied with your life? & Yes / No & \\
\hline 2. & Have you dropped many of your activities and interests? & Yes / No & \\
\hline 3. & Do you feel that your life is empty? & Yes / No & Yes / No \\
\hline 4. & Do you often get bored? & Yes / No & \\
\hline 5. & Are you in good spirits most of the time? & Yes / No & \\
\hline 6. & Are you afraid that something bad is going to happen to you? & Yes / No & \\
\hline 7. & Do you feel happy most of the time? & Yes / No & \\
\hline 8. & Do you often feel helpless? & Yes / No & \\
\hline 9. & Do you prefer to stay at home, rather than going out and doing new things? & Yes / No & \\
\hline 10. & Do you feel you have more problems with memory than most? & Yes / No & \\
\hline 11. & Do you think it is wonderful to be alive? & Yes / No & \\
\hline 12. & Do you feel pretty worthless the way you are now? & Yes / No & \\
\hline 13. & Do you feel full of energy? & Yes / No & \\
\hline 14. & Do you feel that your situation is hopeless? & Yes / No & \\
\hline 15. & Do you think that most people are better off than you are? & TOTAL & \\
\hline & &
\end{tabular}

Scoring:

Assign one point for each of these answers:

$\begin{array}{lllll}\text { 1. No } & \text { 4. Yes } & \text { 7. No } & \text { 10. Yes } & \text { 13. No } \\ \text { 2. Yes } & \text { 5. No } & \text { 8. Yes } & \text { 11. No } & \text { 14. Yes } \\ \text { 3. Yes } & \text { 6. Yes } & \text { 9. Yes } & \text { 12. Yes } & \text { 15. Yes }\end{array}$

A score of $\mathrm{O}$ to 5 is normal. A score above 5 suggests depression.

Fig 1 GDS-15 Used To Assess the Presence or Absence of Depression 


\section{METHODOLOGY}

Approval for carrying out the research was obtained from the Institutional Human Ethics Committee of PSG Institute of Medical Sciences and Research.The study was an Observational study involving collection of data from sample subjects. Elderly patients above the age of 60 years attending the outpatient service of PSG Hospitals were considered. Patients with known psychiatric conditions were excluded. The GDS-15, the short form of Geriatric Depression Scale was used to assess the prevalence of depression among elderly samples. GDS 15 has been represented in Fig 1. A questionnaire was prepared, keeping various causative factors of depression in mind, to assess the possible factors that could cause depression in elderly.An informed consent was obtained from the study population and a detailed one to one interview was conducted. Data was collected from 51 elderly subjects over 60 years of age. The results were tabulated and analysed using GDS-15, questionnaire and statistical tools.

\section{RESULTS}

GDS-15 and the self-designed were analysed and data was tabulated

Data was collected from 51 elderly people.

The age range of the study population was $60-80$ years.

There were 35 males and 16 females.

The prevalence of depression was $58.8 \%$.

Table 1. Prevalence of Depression $n=51$.

\begin{tabular}{|l|l|l|}
\hline Depression & Total number of people & Prevalence \\
\hline Yes & 30 & $58.8 \%$ \\
\hline No & 21 & $41.2 \%$ \\
\hline
\end{tabular}

Table 2. Prevalence of Depression in males and females $\mathrm{n}$ (males) $=35, \mathrm{n}$ (females) $=16$.

\begin{tabular}{|l|l|l|l|}
\hline Depression & $\begin{array}{l}\text { Total number of } \\
\text { people }\end{array}$ & Prevalence & Probability (p) value \\
\hline Males & 19 & $54 \%$ & $\mathrm{p}=0.330$ \\
\hline Females & 11 & $68 \%$ & \\
\hline
\end{tabular}

Table 3. Factors influencing Depression $n=51$.

\begin{tabular}{|l|l|l|l|}
\hline Factors & $\begin{array}{l}\text { Total number of } \\
\text { people }\end{array}$ & $\begin{array}{l}\text { Percentage of people } \\
\text { depressed }\end{array}$ & Probability (p) value \\
\hline Financial fear & & & \\
regarding future & & $80 \%$ & \\
Yes & 25 & $38 \%$ & $\mathrm{p}=0.003$ \\
No & 26 & $75 \%$ & \\
\hline Living alone & & $57 \%$ & $\mathrm{p}=0.493$ \\
Yes & 4 & & \\
No & 47 & & \\
\hline
\end{tabular}


Advanced Medical Sciences: An International Journal (AMS), Vol 2, No.4, November 2015

\begin{tabular}{|l|l|l|l|}
\hline Income sufficiency & & & \\
Yes & 25 & $28 \%$ & $\mathrm{p}=0.000$ \\
No & 26 & $88 \%$ & \\
\hline Recent death in & & & \\
family & 13 & $54 \%$ & $\mathrm{p}=0.673$ \\
Yes & 38 & $61 \%$ & \\
No & & $59 \%$ & \\
\hline Chronic illnesses & 37 & $57 \%$ & $\mathrm{p}=0.881$ \\
Yes & 14 & & \\
No & & \\
\hline
\end{tabular}

\section{DISCUSSION}

Depression is a serious condition for people of all age groups, but for the older population, it is often associated with other comorbid conditions like physical disability, anxiety and dementia that exacerbate distress experienced by older people and their carers [11]. The multifactorial risk for depression involves bio psychosocial context, family history of depression, drug abuse and abuse of other substances like alcohol, somatic diseases with disability and chronic pain, damage to body image, daily loneliness and social isolation, recent grief, fear of death as well as decreased availability of social support and economic resources, capacity of living in community and the need for assistance in day to day activities [12].

In this study, we analysed the prevalence of depression and the factors influencing it among 51 elders belonging to the age group of 60 to 80 years and found that $58.8 \%$ of the elders were depressed. We considered factors like financial fear which may arise in the future, insufficiency of income, recent death, chronic illness and physical disability and loneliness. Our interpretations were based on GDS-15. In our study, the major factors influencing depression based on probability were financial fear and income insufficiency. Although more females were found to be depressed compared to males, sex as a causative factor for depression was not found to be significant. Limitations of this study include the limited sample size and relatively small number of factors considered. Longitudinal studies with a larger sample size needs to be done.

Studies show that depression involves almost $20 \%$ of people over 65 years, $36 \%$ over 75 years and $40 \%$ above the age of 85 years [13]. A study was carried out on 55 elders with depression and found a significant relationship between depression and loneliness [14].

It is important the elderly with depressive illnesses are promptly instituted treatment to prevent major ill effects. Antidepressant therapy should be instituted by selecting drugs that have the best side effect profile and least interactions. The effectiveness of antidepressant drug therapy is the same in elderly as in other population groups. Electroconvulsive therapy can also be used to treat depression [15].

We recommend that success to the management of depression involves valid and reliable selfreport. Improving the identification of people with actual or potential mental health difficulties for referral to general practitioners or mental health practitioners for diagnostic assessment and treatment also plays an important role in preventing major depressive illnesses. More support from government and other institutions to alleviate monetary fear and provision of other services like healthcare and old age homes must be a point of focus. 
Advanced Medical Sciences: An International Journal (AMS), Vol 2, No.4, November 2015

\section{CONCLUSSION}

A study was conducted on 51 elders over the age of 60 years, of which $54 \%$ were males and $68 \%$ were females and it was found that $58.8 \%$ of them suffered from depression. Financial fears regarding future and income insufficiency were found to be the most important factors influencing depression.

\section{ACKNOWLEDGEMENTS}

First and foremost we would like to thank the almighty. We thank the Department of Community Medicine, PSG Institute of Medical Sciences and Research for helping us. Our sincere thanks to Dr. Thomas V Chacko, Professor and Head of Department of Community Medicine, PSG Institute of Medical Sciences and Research for providing us this opportunity through the Problem Solving for Better Health Programme. We would like to thank our guide Dr. K Suvetha who stood by our side and helped us carry out this research of ours perfectly at each and every step. We also thank Dr. Y S Sivan who encouraged us throughout our work. Finally we wish to thank the study participants for sparing their valuable time and for providing the information which enabled us to complete our research.

\section{REFERENCES}

[1] Manjubhashini S, Krishnababu G and Krishnaveni A (2013) Epidemological study of depression among population above 60 years in Vishakapatnam, India. Int J Med Sci Public Health, 2(3): 695 702 .

[2] Sanghamitra Maulik and Aparajita Dasgupta (2012) Depression and its determinants in the rural elderly of WestBengal - a cross sectional study. Int J Biol Med Res, 3(1): 1299-1302.

[3] David C Steffens, Ingmar Skoog, Maria C Norton, Andrea D Hart, JoAnn T Tschanz, Brenda L Plassman, Bonita W Wyse, Kathleen A Welsh and John C S Breitner (2000) Prevalence of Depression and its treatment in an elderly population, Arch Gen Psychiatry. 57:601-607.

[4] Lebowitz BD, Pearson JL, Schneider LS, Reynolds CF, Alexopoulos GS, Bruce MI, Conwell Y, Katz IR, Meyers BS, Morrison MF, Mossey J, Niederehe G and Parmelee P (1997) Diagnosis and treatment of depression in late life: consensus statement update. Journal of the American Medical Association. 278(14):1186-1190.

[5] R Michael Bagby, Andrew G Ryder, Deborah R Schuller and Margarita B Marshall (2004) The Hamilton Depression Rating Scale: Has the Gold Standard Become a Lead Weight? The American Journal of Psychiatry. Volume 161 Issue 12 pp. 2163-2177.

[6] Sean Joe, Michael E Woolley, Gregory K Brown, Marjan Ghahramanlou-Holloway and Aaron T Beck (2008) Psychometric Properties of the Beck Depression Inventory-II in Low-Income, African American Suicide Attempters. J Pers Assess. 90950: 521-523.

[7] Pracheth R, Mayur SS and Chowti JV (2013) Geriatric Depression Scale: A tool to assess depression in elderly. Int J Med Sci Public Health. 2(1): 31-35

[8] Janet B W Willams and Kenneth A Kobak (2008). Development and reliability of a structured interview guide for the Montgomery-Asberg Depression Rating Scale (SIGMA). The British Journal of Psychiatry. 192(1) 52-58.

[9] Grace G Aikman and Mary E Oehlert (2000) Geriatric Depression Scale: Long Form Versus Short Form. Clinical Gerontologist, Vol. 22(3/4) 2000.

[10] Linda G Marc, Patrick J Raue and Martha L Bruce (2008) Screening Performance of the Geriatric Depression Scale (GDS-15) in a Diverse Elderly Home Care Population. Am J Geriatr Psychiatry. 16(11): 914-921.

[11] Briony Dow, Betty Haralambous, Xiaoling Lin, Carolyne Jones, Jean Tinney and Christina Bryant (2009) Beyondblue Depression in older age: A scoping study. National Ageing Research Institute (NARI). 
Advanced Medical Sciences: An International Journal (AMS), Vol 2, No.4, November 2015

[12] Bulbena A and Berrios G E (1986) Pseudodementia Facts and Figures. Brit J Pscychiatry. 148:87-94.

[13] Stek ML, Vinkers DJ, Gussekloo J, Van der Mast RC, Beekman AT and Westendorp RG (2006) Natural history of depression in the oldest old: population-based prospective study. Br J Psychiatry. 188:65-9.

[14] Archana S and Nishi M (2009) Loneliness, depression and sociability. Ind Psychiatry J, 18(1): 5155.

[15] Bonnie SW (2011) Geriatric depression: The use of antidepressants in the elderly. BC Medical Journal, Vol 53, No 7, Pg 341-347.

\section{Authors}

1. A K Prahshanth, Continuous Rotatory Residential Intern, PSG Institute of Medical Sciences and Research, Coimbatore

2. M PerathuKannu Rakesh, Continuous Rotatory Residential Intern, PSG Institute of Medical Sciences and Research, Coimbatore

3. V Praveena, Continuous Rotatory Residential Intern, PSG Institute of Medical Sciences and Research, Coimbatore

4. A Preethi, Continuous Rotatory Residential Intern, PSG Institute of Medical Sciences and Research, Coimbatore

5. S Prithvi, Continuous Rotatory Residential Intern, PSG Institute of Medical Sciences and Research, Coimbatore

6. R Priyadharshini, Continuous Rotatory Residential Intern, PSG Institute of Medical Sciences and Research, Coimbatore

7. Dr. K Suvetha, Associate Professor, Department of Community Medicine, PSG Institute of Medical Sciences and Research, Coimbatore 